\title{
Purulent Pericarditis Accompanying Pericardial Abscess Induced by Nocardia in an Immunocompromised Patient
}

Akira Takashima, MD, PhD; Shusuke Yagi, MD, PhD; Koji Yamaguchi, MD, PhD;

Syunsuke Watanabe, MD; Nobuaki Yamamoto, MD, PhD; Hiroyuki Ito, MD;

Muneyuki Kadota, MD, PhD; Tomoya Hara, MD, PhD; Hiromu Yamazaki, MD, PhD;

Takayuki Ise, MD, PhD; Kenya Kusunose, MD, PhD; Takeshi Tobiume, MD;

Hirotsugu Yamada, MD, PhD; Takeshi Soeki, MD, PhD;

Tetsuzo Wakatsuki, MD, PhD; Masataka Sata, MD, PhD
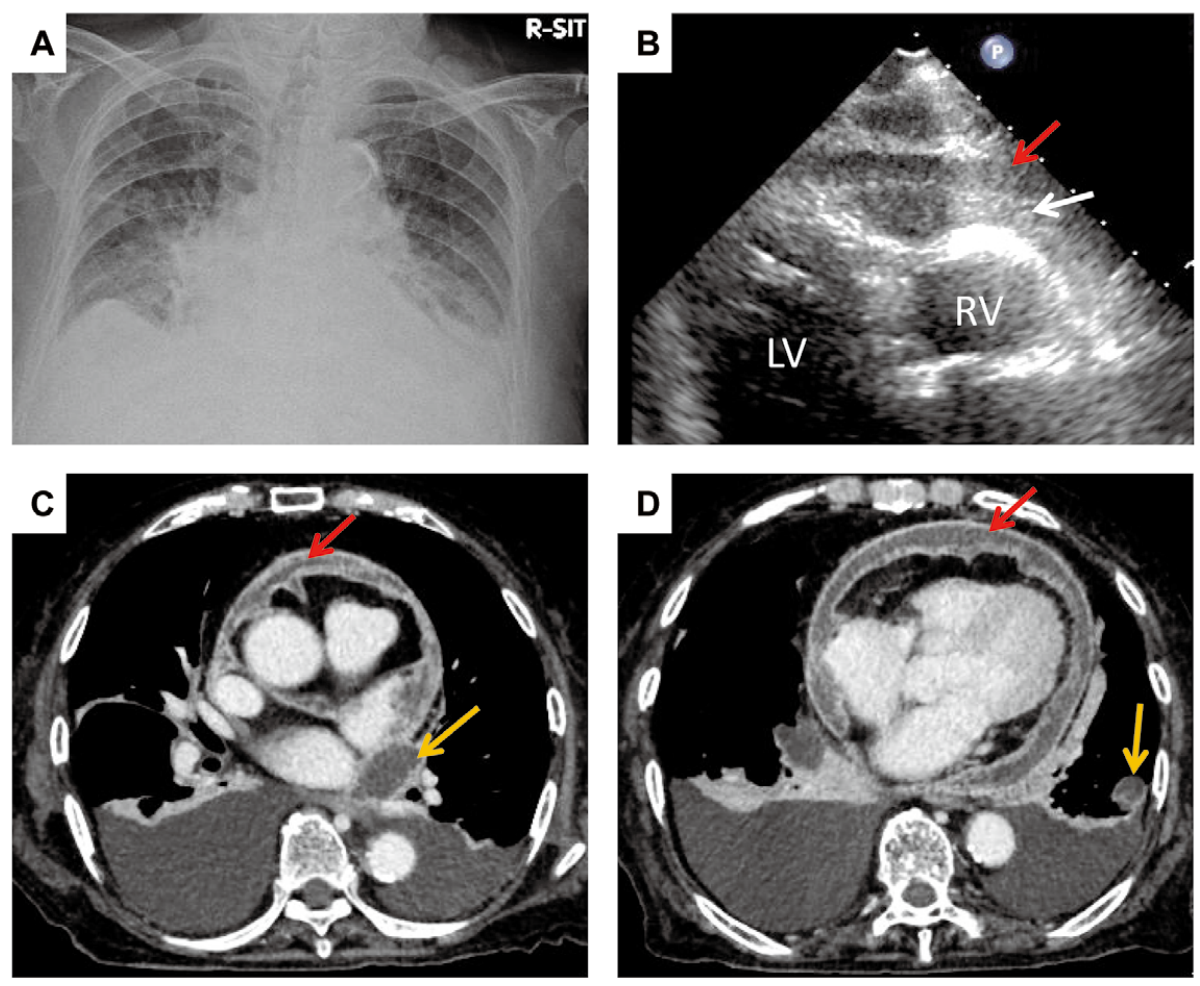

Figure 1. Chest radiography, transthoracic echocardiography, and contrast-enhanced computed tomography (CT) in a patient with purulent pericarditis and abscess formation involving both the heart and left lung. (A) Chest radiogram showing cardiomegaly, pulmonary congestion, and bilateral blunting of the costophrenic angle. (B) Transthoracic echocardiography, parasternal long-axis view, showing high-density, hemorrhagic or purulent, pericardial effusion (red arrow) and thickened epicardial adipose tissue (white arrow). LV, left ventricle; RV, right ventricle. (C,D) CT showing pericardial effusion (red arrows), (C) an abnormal mass adjacent to the left atrium (yellow arrow), and (D) and an abnormal mass in the left lung (yellow arrow).

Received June 1, 2016; revised manuscript received August 5, 2016; accepted August 16, 2016; released online September 15, 2016 Time for primary review: 19 days

Department of Cardiovascular Medicine (A.T., S.Y., K.Y., H.I., M.K., T.H., H. Yamazaki, T.I., K.K., T.T., H. Yamada, T.S., T.W., M.S.), Division of Pathology (S.W.), Tokushima University Hospital, Tokushima; Department of Clinical Neuroscience, Institute of Biomedical Sciences, Tokushima University, Tokushima (N.Y.), Japan

Mailing address: Akira Takashima, MD, PhD, Department of Cardiovascular Medicine, Tokushima University Hospital, Tokushima 770-8503, Japan. E-mail: takashima_narutohp@yahoo.co.jp

ISSN-1346-9843 doi:10.1253/circj.CJ-16-0531

All rights are reserved to the Japanese Circulation Society. For permissions, please e-mail: cj@j-circ.or.jp 

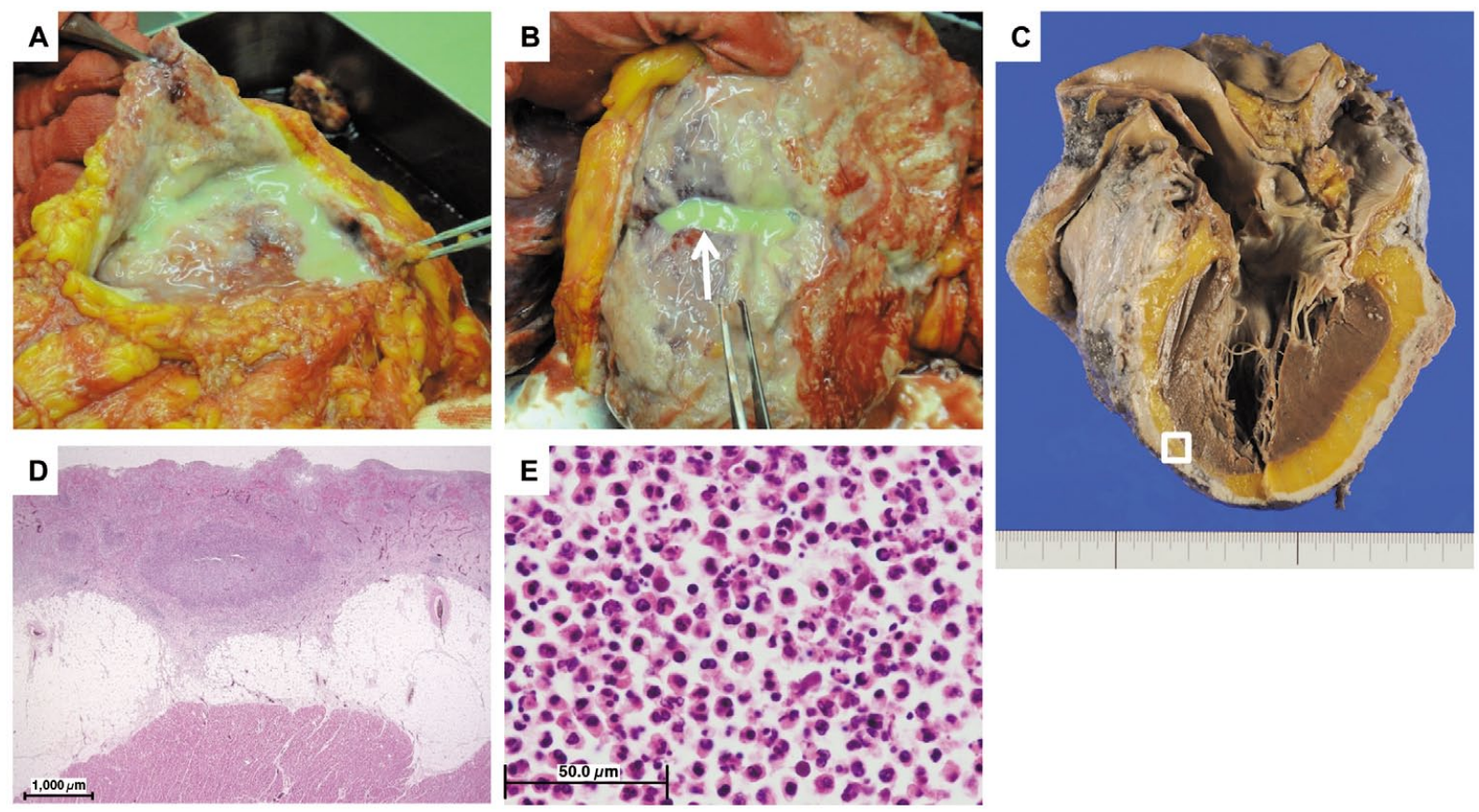

Figure 2. Macroscopic and microscopic autopsy findings in a patient with purulent pericarditis. (A) Pericardiectomy of the autopsied heart showing purulent pericardial effusion. (B) The abnormal mass alongside the left atrium contains pus (arrow). (C) Autopsied heart. (D) Histopathology of tissue sampled from the white box area in (C): persistent inflammation has caused severe inflammatory cell infiltration (hematoxylin-eosin staining); and (E) high magnification of (D) showing abundant neutrophils. Scale bars: (D) $1,000 \mu \mathrm{m}$; (E) $50 \mu \mathrm{m}$.

A 91-year-old woman presented to hospital with persistent low-grade fever despite several courses of antibiotics. She had a history of myasthenia gravis and had been taking tacrolimus for immunosuppression for 8 years. Physical examination, including blood pressure $(128 / 88 \mathrm{mmHg})$, body temperature $\left(36.8^{\circ} \mathrm{C}\right)$, and lack of paradoxical pulse, were unremarkable, except for increased heart rate (100 beats/min) and reduced lung sounds on both sides. Blood tests showed leukocytosis (white blood cell count, 20,000/ $\mu$ ) with elevated C-reactive protein $(8.89 \mathrm{mg} / \mathrm{dl})$ and hypoalbuminemia $(2.4 \mathrm{~g} / \mathrm{dl})$. Chest radiogram showed cardiomegaly, pulmonary congestion, and bilateral blunting of the costophrenic angle (Figure 1A). Twelve-lead electrocardiogram showed no remarkable changes. Transthoracic echocardiography showed high-density, hemorrhagic or purulent, pericardial effusion, but there was no sign of heart failure, cardiac tamponade including right ventricular or right atrial collapse, constrictive (effusive) pericarditis including respiratory variations of the inferior vena cava diameter or septal bounce motion, or infective endocarditis (Figure 1B; Movie S1). On contrast-enhanced computed tomography $(\mathrm{CT})$, pericardial effusion with high CT density, an abnormal mass between the left atrium and bronchus, nodular mass in the left lung, and a large volume of pleural effusion on both sides presumably caused by hypoalbuminemia, were noted (Figures 1C,D). Although bacterial or malignant pericarditis was suspected, diagnostic pericardiocentesis could not be performed because the volume of pericardial effusion was considered too low for the procedure to be carried out safely, and the patient and her family refused surgical drainage. No bacteria were detected from sputum or sequential blood cultures. Despite ceftriaxone as diagnostic treatment targeting
Gram-positive and Gram-negative bacteria, the patient died after 6 days in hospital, and autopsy was performed. On autopsy, the pericardial effusion was purulent in nature and the abnormal mass adjacent to the left atrium was an abscess (Figures 2A,B). On pathology of the autopsied heart, significant neutrophil infiltration was noted in the pericardium (Figures 2C-E), and bacterial culture of the pus yielded Nocardia species. As in the heart, pathology of the nodular mass in the left lung indicated abscess with neutrophil infiltration.

Infections caused by Nocardia species usually cause a wide variety of diseases in immunocompromised patients. ${ }^{1}$ In humans, Nocardia species may enter the body by inhalation, with the possibility of resultant pulmonary nocardiosis pneumonia, lung abscess, or cavitary lesions, or by direct contact via a cut or abraded skin, with possible dissemination to the brain, kidneys, joints, heart, eyes, or bones. ${ }^{2}$ Nocardia pericarditis may lead to purulent pericarditis and is associated with the development of cardiac tamponade or pericardial constriction. ${ }^{3,4}$ Therefore, it is important to perform surgical drainage in purulent pericarditis. ${ }^{5}$ The identification of Nocardia is difficult because it is a slow-growing bacteria and can be easily obscured by other bacteria with more rapid growth in specimens such as sputum containing mixed flora. ${ }^{1}$ Antibiotic treatment with 2 or 3 i.v. agents such as trimethoprim-sulfamethoxazole, imipenem/cilastatin, or amikacin while awaiting the results of susceptibility testing is required, and should be given for at least 3-6 weeks until the patient shows clinical improvement. ${ }^{3}$ Cardiac abscesses have previously been detected as perivalvular or atrial septal abscesses with infective endocarditis or myocardial abscess with myocardial infarction. ${ }^{6-9}$ The present case, however, is unique in that the 
abscess was located in the pericardium, which might have been caused by hematogenous dissemination of Nocardia organisms from the lung abscess. In this case, treatment of pericarditis was difficult because the patient and her family did not desire surgical drainage because of the advanced age of the patient, and the safety of pericardiocentesis was in doubt because of the small volume of fluid. In addition, it was difficult to rule out lung cancer and pericardial carcinomatosis until autopsy. In immunosuppressed patients with pericardial effusion of unknown cause, Nocardia pericarditis should be considered in the differential diagnosis.

\section{Acknowledgments}

None.

\section{Disclosures}

The authors declare no conflicts of interest.

\section{References}

1. Ambrosioni J, Lew D, Garbino J. Nocardiosis: Updated clinical review and experience at a tertiary center. Infection 2010; 38: 89-97.

2. Kandi V. Human Nocardia infections: A review of pulmonary nocardiosis. Cureus 2015; 7: e304, doi:10.7759/cureus.304.

3. Sirijatuphat R, Niltwat $S$, Tiangtam O, Tungsubutra W. Purulent pericarditis and cardiac tamponade caused by Nocardia farcinica in a nephrotic syndrome patient. Intern Med 2013; 52: 2231-2235.

4. Kessler R, Follis F, Daube D, Wernly J. Constrictive pericarditis from Nocardia asteroides infection. Ann Thorac Surg 1991; 52: $861-862$.

5. Rubin RH, Moellering RC Jr. Clinical, microbiologic and therapeutic aspects of purulent pericarditis. Am J Med 1975; 59: 68-78.

6. Brown RE, Chiaco JM, Dillon JL, Catherwood E, Ornvold K. Infective endocarditis presenting as complete heart block with an unexpected finding of a cardiac abscess and purulent pericarditis. J Clin Med Res 2015; 7: 890-895.

7. Finley RW, Marr JJ. Anaerobic myocardial abscess following myocardial infarction. Am J Med 1985; 78: 513-514.

8. Park JS, Hong YS, Choi BJ, Choi SY, Yoon MH, Hwang GS, et al. Abscess pocket in the vegetation confirmed on 3-dimensional transesophageal echocardiography. Circ J 2014; 78: 1995-1996.

9. Naganuma T, Takagi K, Fujino Y, Kobayashi T, Mitomo S, Akita $\mathrm{M}$, et al. Valsalva sinus perforation into the right atrium due to infective endocarditis of transcatheter heart valve. Circ J 2015; 79: $1133-1135$.

\section{Supplementary Files}

Supplementary File 1

Movie S1. Transthoracic echocardiography image from the parasternal long-axis view reveals high-density, hemorrhagic or purulent, pericardial effusion and thickened epicardial adipose tissue.

Please find supplementary file(s);

http://dx.doi.org/10.1253/circj.CJ-16-0531 